\title{
Investigating how high school deaf students spend their leisure time
}

\author{
Allahyar Arabmomeni ${ }^{a^{*}}$, Khodayar Momeni ${ }^{\mathrm{b}}$, Mohammad Reza Iravanic ${ }^{\mathrm{c}}$, Faezeh Taghipour ${ }^{\mathrm{d}}$
}

${ }^{a}$ Department of Human Science of Islamic Azad University Khomeinishahr Branch, Isfahan, Iran

${ }^{b}$ Islamic Azad University of Kerman, Science and Research, Kerman Branch, Iran

${ }^{c}$ Department of Social Work, Islamic Azad University of Khomeinishahr, Khomeinishahr Branch, Daneshjou Blvd, Iran

${ }^{d}$ Assistant Professor, Department of Cultural Management Khorasgan (Isfahan) Branch, Islamic Azad University, Isfahan, Iran

\begin{tabular}{|c|c|}
\hline A R T I C L E I N F O & A B S T R A C T \\
\hline $\begin{array}{l}\text { Article history: } \\
\text { Received June 28, } 2012 \\
\text { Received in Revised form } \\
\text { August, 26, } 2012 \\
\text { Accepted 29 August } 2012 \\
\text { Available online } \\
\text { 11 September } 2012 \\
\text { Keywords: } \\
\text { People with disability } \\
\text { Deaf student } \\
\text { Entertainment }\end{array}$ & $\begin{array}{l}\text { This paper presents an investigation on deaf students' interests in spending their leisure times. } \\
\text { We design a questionnaire and distribute among all deaf students who are enrolled in high } \\
\text { schools in two provinces of Iran. The questionnaire consists of three parts, in the first part, we } \\
\text { ask female and male deaf students about their interests in various entertainment activities in } \\
\text { Likert scale. In terms of gender, we find out that walking inside or outside house is number one } \\
\text { favorite exercise for female students while male students mostly prefer to walk on the streets. } \\
\text { Although male students prefer to go biking or running activities, female students prefer to go } \\
\text { for picnic or similar activities. This could be due to limitations on female for running or biking } \\
\text { inside cities. While going to picnic with members of family or friends is the third popular } \\
\text { activity for male students, stretching exercises is third most popular activity among female } \\
\text { students. Breathing exercise is the fourth most popular activity among both male and female } \\
\text { students. The second part of the survey is associated with the barriers for having no exercise } \\
\text { among deaf students. According to our survey, while lack of good attention from public and } \\
\text { ordinary people on exercising deaf students is believed to be number one barrier among male } \\
\text { students, female students blame lack of transportation facilities as the most important barrier. } \\
\text { However, both female and male students believe these two items are the most important factors } \\
\text { preventing them to exercise. Lack of awareness for exercising deaf students and lack of good } \\
\text { recreational facilities are the third most important barriers among male and female students. }\end{array}$ \\
\hline
\end{tabular}

(C) 2012 Growing Science Ltd. All rights reserved.

\section{Introduction}

Leisure plays an important role on releasing stress and refreshing people's bad energies (Green et al., 1990; Schoenborn \& Barnes, 2002; Leitner \& Leitner, 2004; Torkildsen, 2005). Sjolie and Thuen (2002) performed an investigation on both rural and urban adolescents spent more time on sedentary activities, such as watching TV/video and playing TV/data-games, than on normal physical activity.

* Corresponding author. Tel: +989133688572

E-mail addresses: arabmomeni@iaukhsh.ac.ir (A. Arabmomeni) 
They found no differences between the two groups based on activity patterns. They also reported positive correlations between walking or cycling from home to school and walking or cycling to regular activities. According to multiple regression analysis, urban area, female gender and distance walked or cycled to school forecasted increased walking or cycling to activities. Their results also confirmed other studies on adolescents, indicating that much more time was spent on sedentary rather than on physical activity.

Crombie et al. (2008) investigated why older people were unwilling to participate in leisure time physical activity and to determine appropriate strategies to encourage increased activity. They concluded that increasing leisure time physical activities caused major challenges. They reported that desirable levels of activity in older people would require to be changed and any action would be necessary to relieve physical symptoms and could address fears about perceived capability to undertake physical activity. They also reported that easily accessible facilities could be necessity to encourage participation in physical activity. Larson and Seepersad (2003) investigated adolescents leisure time in United States including partying, sports, and American experiment

Tasai (2005) investigated the ways, which perceptions of positive outcomes of engagement in regular active recreation could impact engagement interest, engagement intentions and subsequent engagement in regular active recreation in the two contrasting cultures of Hong Kong and Australia by investigating 927 Hong Kong and 1,018 Australian university students completed survey questionnaires. The study reported that having an interest in the activities played vital role, which led to enduring engagement in active recreation. Beliefs about physiological advantages of active recreation had no substantial influence on young people's engagement intention, interest and actual engagement. Perception of affective outcomes was an effective motivator for Australian but not for Hong Kong students. Perceptions of psychological outcomes were another important predictor only for Hong Kong students. The findings recommended that cultural values and social, physical, and leisure environments could moderate the cognitive processes, which underlie engagement in regular active recreation.

These days, we live in a society where people may live with some sort of disabilities and various governmental or non-governmental organizations try to setup supportive rules and regulations to provide equal living opportunities. Deaf people are among people who live with disabilities and their problems need to be considered very carefully. During the past few years, there have been tremendous efforts on investigating issues influencing people with disabilities. Wei et al. (2012), for instance, investigated dental problem among deaf students.

Mirzaee et al. (2011) considered self-handicapping among blind and deaf students where 84 blind students and 64 deaf students were selected through multi-cluster sampling. The results demonstrated that the blinds and the deaf did not differ in adopting claimed self-handicapping mechanism and general self-handicapping. Comparing the blind students, the deaf students demonstrated a greater implementation of behavioral self-handicapping mechanism. Molander et al. (2010) discussed the ambiguity among deaf people. They investigated the ambiguity of words and signs as a resource or obstacle in group discussions. They studied how deaf and hearing students aged 13-15 years elaborated on ecological concepts through dialogue. They used a group interviews with 14 hearing and 18 deaf students and probes were used to initiate talks about the various meanings of ecological concepts including producer, consumer, nutrients/nutriment, food-chain and cycles. The results demonstrated that the dialogues were less elaborated for deaf learners than for hearing learners were.

In this paper, we present an empirical study to find out how deaf student spend their life for entertainment. The proposed study of this paper first presents details of study in section 2. Section 3 provides details of our findings and finally, concluding remarks are given in the last to summarize the contribution of the paper. 


\section{The proposed study}

The purpose of this study is to determine the main personal activities among deaf students who are enrolled in high schools in two provinces of Kernan and Farse of Iran. The proposed study design and distributed a questionnaire among all 170 students in these two provinces during the year of 2011. There were 100 male and 70 female students in this survey and the study collected the information using the whole population. The questionnaire consists of three parts with 41questions. The first part of the questionnaire consists of 15 questions associated with different types of activities in Likert scale in six various scales from very much to absolutely nothing. The second part of survey consists of 12 questions in three-level Likert scale, low, average and high. The last part of the questionnaire also consists of 14 questions and it is associated with barriers on having physical activities in Likert scale in six different scales from very much to absolutely nothing. The overall validity of the questionnaire was confirmed using five university experts' feedback, where Cronbach alpha was calculated as 0.89 for the whole questionnaire and for each part of the questionnaire, it was calculated as $0.78,0.75$ and 0.79 , respectively.

\section{The results}

The first question of the survey is associated with average times they spend on leisure and entertainment and the results of the survey is shown in Fig. 1 as follows,

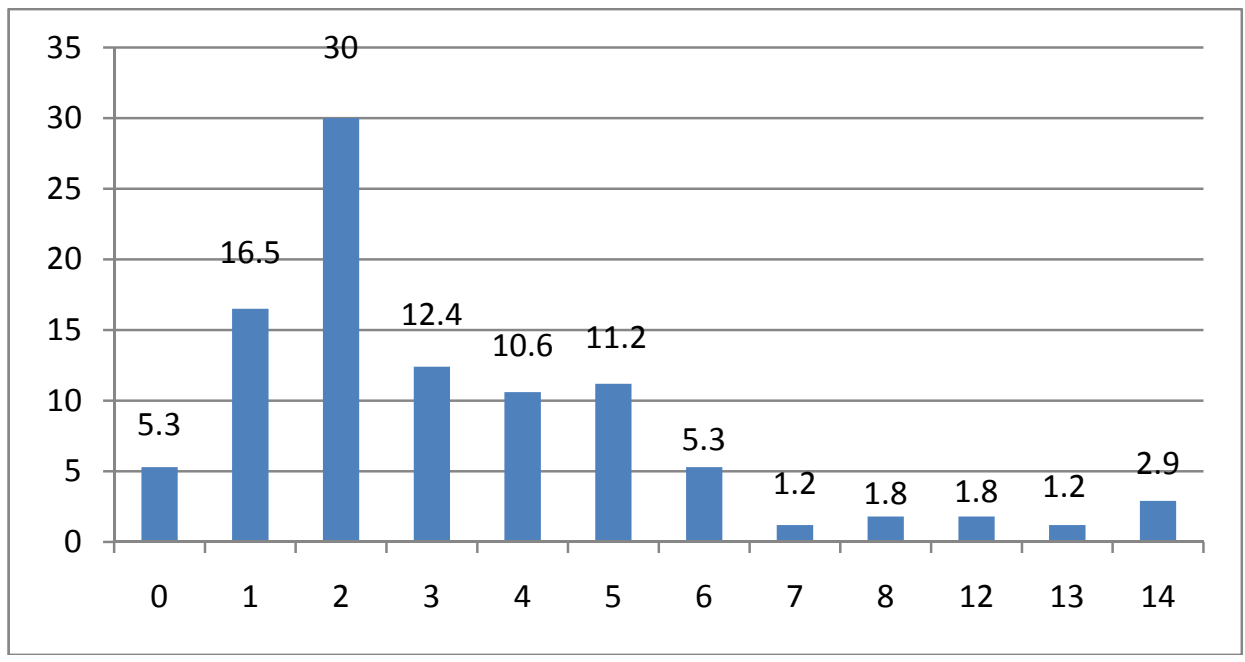

Fig. 1. The amount of deaf time students spent per day in terms of percentage

We have also asked the students about the amount of time they spent on physical activities in recreational centers and $11.9 \%$ of the students indicated they had never used such facilities, $42.6 \%$ reported that they occasionally participated in gym facilities and $45.5 \%$ of the students reported that they had taken part in such facilities, regularly. We have also asked them whether they used public entertainment facilities located in their living area. According to our survey, 29.7\% (24.2\% male and $5.5 \%$ female) of the students claimed they regularly exercised in such places. In addition, $64.1 \%$ (39.7\% male and $24.2 \%$ female) students reported that they occasionally use public facilities and $6.3 \%$ reported that they had never used such facilities. Physical activities are among the most important concern of this survey and 12 questions of this survey was dedicated to this issue. In our survey, $48.2 \%$ of the participants (15.9\% male and $32.4 \%$ female) hardly participated in physical activities, $42.9 \%$ (34.9\% male and $8.2 \%$ female) of the participants had an average participation in physical activities and $8.8 \%$ (8.2\% male and $0.6 \%$ female) were relatively active in physical activities. Table 1 shows details of our survey in terms of different questions of the survey. 
Based on the results of Table 1, walking on street for entertainment, long run exercise such as biking, running, etc., going to picnic with family and relative and breathing exercises are among the most important activities considered among deaf students. However, when we look at their results in terms of gender, we find out that walking inside or outside house is number one favorite exercise for female students while male students mostly prefer to walk on the streets. Although male students prefer to go biking or running activities, female students prefer to go for picnic or similar activities. This could be due to limitations on female for running or biking insider cities. While going to picnic with members of family or friends is the third popular activity for male students, stretching exercises is third most popular activity among female students. Breathing exercise is the fourth most popular activity among both male and female students.

\section{Table 1}

Ranking of different activities in terms of physical activities based on t-student test

\begin{tabular}{lllllll}
\hline & Male & & Female & Total \\
\hline Activity & Mean & Rank & Mean & Rank & Mean & Rank \\
\hline Walking on street for entertainment & 2.04 & 1 & 1.37 & 1 & 1.76 & 1 \\
Long run exercise such as biking, running, etc. & 2.01 & 2 & 1.30 & 9 & 1.72 & 3 \\
Going to picnic with family and relative & 1.98 & 3 & 1.40 & 5 & 1.74 & 2 \\
Breathing exercises & 1.88 & 4 & 1.49 & 2 & 1.72 & 4 \\
Going to parks for entertainment & 1.84 & 5 & 1.37 & 6 & 1.65 & 6 \\
Balance exercises & 1.79 & 6 & 1.26 & 10 & 1.57 & 8 \\
Walking inside or outside house & 1.77 & 7 & 1.57 & 1 & 1.69 & 5 \\
Playing physical activities with family members & 1.77 & 8 & 1.4 & 4 & 1.62 & 7 \\
Strength Training & 1.70 & 9 & 1.33 & 8 & 1.55 & 9 \\
Stretching exercises & 1.63 & 10 & 1.41 & 3 & 1.54 & 10 \\
Handicraft exercises & 1.48 & 11 & 1.21 & 11 & 1.37 & 11 \\
Playing Soccer & 1.42 & 12 & 0.07 & 16 & 0.86 & 12 \\
Playing volleyball & 0.47 & 13 & 1.02 & 12 & 0.72 & 13 \\
Swimming & 0.44 & 14 & 0.157 & 14 & 0.32 & 14 \\
Basketball & 0.09 & 16 & 0.10 & 16 & 0.094 & 16 \\
Body building & 0.05 & 16 & 0.17 & 13 & 0.10 & 15 \\
Playing chess & 0.05 & 17 & 0.00 & 18 & 0.05 & 17 \\
Playing badminton & 0.01 & 18 & 0.057 & 17 & 0.029 & 18 \\
Playing Tennis & 0.01 & 19 & 0.00 & 19 & 0.01 & 19 \\
\hline
\end{tabular}

The second part of the survey is associated with the barriers for having no exercise among deaf students. Table 2 shows the barriers for not having any exercise among deaf students.

\section{Table 2}

Ranking of different entertainment activities based on t-student test

\begin{tabular}{|c|c|c|c|c|c|c|}
\hline & Male & & Female & & Total & \\
\hline Activity & Mean & Rank & Mean & Rank & Mean & Rank \\
\hline Lack of need for exercising & 4.21 & 2 & 3.64 & 5 & 3.98 & 1 \\
\hline Lack of transportation facilities & 3.96 & 5 & 4 & 1 & 3.98 & 2 \\
\hline $\begin{array}{l}\text { Paying no attention on behalf of public towards exercising } \\
\text { of deaf students }\end{array}$ & 4.28 & 1 & 3.39 & 9 & 3.91 & 3 \\
\hline Lack of awareness for exercising deaf students & 4.13 & 3 & 3.53 & 7 & 3.88 & 4 \\
\hline Financial problems & 3.79 & 9 & 3.96 & 2 & 3.85 & 5 \\
\hline Lack of good recreational facilities & 3.79 & 10 & 3.81 & 3 & 3.80 & 6 \\
\hline Lack of suitable facilities proportion to students' needs & 3.85 & 6 & 3.54 & 6 & 3.72 & 7 \\
\hline Lack of a good training for exercise & 3.70 & 12 & 3.74 & 4 & 3.72 & 8 \\
\hline Lack of support on behalf of authorities & 3.98 & 4 & 3.30 & 12 & 3.70 & 9 \\
\hline Shortage of coach to train students & 3.83 & 7 & 3.44 & 8 & 3.67 & 10 \\
\hline Difficulties to hear among deaf students & 3.83 & 8 & 3.34 & 11 & 3.63 & 11 \\
\hline Lack of security in city & 3.72 & 11 & 3.37 & 10 & 3.58 & 12 \\
\hline Personal problems & 3.32 & 13 & 3.10 & 14 & 3.23 & 13 \\
\hline Fear of injuries & 3.07 & 14 & 3.13 & 13 & 3.09 & 14 \\
\hline
\end{tabular}


As we can observe from the results while lack of good attention from public and ordinary people on exercising deaf students is believed to be number one barrier among male students, female students blame lack of transportation facilities as the most important barrier. However, both female and male students believe these two items are the most important factors preventing them to exercise. Lack of awareness for exercising deaf students and lack of good recreational facilities are the third most important barriers among male and female students.

Finally, we have looked at the relative importance of different entertainment deaf students in terms of their gender and the results are summarized in Table 3.

\section{Table 3}

Ranking different entertainment activities among deaf students based on t-student test

\begin{tabular}{|c|c|c|c|c|}
\hline & Male & & Femal & \\
\hline Activity & Mean & Rank & Mean & Rank \\
\hline Watching TV & 4.58 & 1 & 3.94 & 2 \\
\hline Entertaining with mobile devices & 4.75 & 2 & 3.54 & 4 \\
\hline Chatting with friends & 3.95 & 3 & 4.09 & 1 \\
\hline Watching DVD or movies & 3.94 & 4 & 3.60 & 3 \\
\hline Taking part in stadiums as fans & 3.83 & 5 & 3.49 & 5 \\
\hline Taking part in athletic activities & 3.74 & 6 & 2.73 & 9 \\
\hline Participating in social activities with relatives & 3.59 & 7 & 3.14 & 6 \\
\hline Playing different games & 3.39 & 8 & 2.50 & 12 \\
\hline Purchasing as entertainment & 3.31 & 9 & 2.69 & 11 \\
\hline Surfing the internet & 3.26 & 7 & 2.80 & 8 \\
\hline Reading books, magazines, etc. & 3.14 & 11 & 3.03 & 7 \\
\hline Attending museum, theaters, etc. & 3.06 & 12 & 2.69 & 10 \\
\hline Attending cinemas & 2.93 & 13 & 2.09 & 14 \\
\hline Handicraft works & 2.84 & 14 & 2.26 & 13 \\
\hline
\end{tabular}

As we can observe from the results of Table 3, watching TV is the first important entertainment among male students while chatting with friends is the most popular hobby among female students. While entertaining with new mobile devices is the second most important item among male's students watching TV comes among male students. In summary, watching TV, entertaining with mobile devices, chatting with friends and watching DVD or movies are the most important items influencing deaf students' free times.

\section{Conclusion}

In this paper, we have performed a study to investigate deaf students' interests in spending their leisure times. We have designed a questionnaire and distributed among all deaf students who participated in high schools in two provinces of Iran. The questionnaire consisted of three parts, in the first part, we have asked female and male deaf students about their interests in different entertainment activities in Likert scale. When we looked at their results in terms of gender, we have found out that walking inside or outside house is number one favorite exercise for female students while male students mostly prefer to walk on the streets. Although male students prefer to go biking or running activities, female students prefer to go for picnic or similar activities. This could be due to limitations on female for running or biking insider cities. While going to picnic with members of family or friends is the third popular activity for male students, stretching exercises is third most popular activity among female students. Breathing exercise is the fourth most popular activity among both male and female students. The second part of the survey is associated with the barriers for having no exercise among deaf students. According to our survey, while lack of good attention from public and ordinary people on exercising deaf students was believed to be number one barrier among male students, female students blamed lack of transportation facilities as the most important barrier. However, both female and male students believed these two items were the most important factors 
preventing them to exercise. Lack of awareness for exercising deaf students and lack of good recreational facilities are the third most important barriers among male and female students. The last part of the survey attempted to detect important entertainment activities. Watching TV, entertaining with mobile devices, chatting with friends and watching DVD or movies were the most important items influencing deaf students' free times.

\section{Acknowledgement}

The authors would like to thank the officials of high schools who kindly supported our survey. We are also grateful to constructive comments on earlier version of this paper.

\section{References}

Crombie, I.K., Irvine, L., Williams, B., McGinnis, A.R., Slane, P.W., Alder, E.M., \& McMurdo, M.E.T. (2008). Why older people do not participate in leisure time physical activity: A survey of activity levels. Beliefs and Deterrents, 33, 287-292.

Green, E., Hebron, S., \& Woodward, D. (1990). Women's Leisure, What Leisure? Basingstoke: Macmillan.

Leitner, M. J., \& Leitner, S.F. (2004). Leisure Enhancement, $3^{\text {rd }}$ ed., New York: The Haworth press.

Larson, R. \& Seepersad, S. (2003). Adolescents leisure time in United States: Partying, Sports, and American Experiment. New Directions for Childs and adolscent development, 3(99), 53-64.

Mirzaee, M., Farahani, A., Heidari, M., \& Amrai, K. (2011). Comparing self-handicapping among blind and deaf students. Procedia - Social and Behavioral Sciences, 15, 777-779.

Molander, B.O., Halldén, O., \& Lindahl, C. (2010). Ambiguity - A tool or obstacle for joint productive dialogue activity in deaf and hearing students' reasoning about ecology. International Journal of Educational Research, 49(1), 33-47

Schoenborn, C.A., \& Barnes, P.M. (2002). Leisure-time physical activity among adults: United States 1997-1998, Hyattsville, Maryland: National Center for Health Statistics. Advanced Data from Vital and Health Statistics, no.325.

Sjolie, A. N., \& Thuen, F. (2002). School journeys and leisure activities in rural and urban adolescents in Norway. Health Promotion International, 17(1), 21-30.

Tasai, E. (2005). A cross cultural study of the influence of perceived positive outcomes on participation in regular active recreation: Hong Kong and Australian University Students. Leisure Science, 27(5), 385-404.

Torkildsen, G. (2005). Leisure and Recreation Management, London: Routledge.

Wei, H., Wang, Y.L., Cong, X.N., Tang, W.Q., \& Wei, P.M.(2012). Survey and analysis of dental caries in students at a deaf-mute high school. Research in Developmental Disabilities, 33(4), 1279-1286. 